\title{
Discriminative-stimulus and time-course effects of kava-kava (Piper methysticum) in rats
}

Natalie R. Bruner

West Virginia University

Follow this and additional works at: https://researchrepository.wvu.edu/etd

\section{Recommended Citation}

Bruner, Natalie R., "Discriminative-stimulus and time-course effects of kava-kava (Piper methysticum) in rats" (2008). Graduate Theses, Dissertations, and Problem Reports. 4358.

https://researchrepository.wvu.edu/etd/4358

This Thesis is protected by copyright and/or related rights. It has been brought to you by the The Research Repository @ WVU with permission from the rights-holder(s). You are free to use this Thesis in any way that is permitted by the copyright and related rights legislation that applies to your use. For other uses you must obtain permission from the rights-holder(s) directly, unless additional rights are indicated by a Creative Commons license in the record and/ or on the work itself. This Thesis has been accepted for inclusion in WVU Graduate Theses, Dissertations, and Problem Reports collection by an authorized administrator of The Research Repository @ WVU. For more information, please contact researchrepository@mail.wvu.edu. 
Discriminative-stimulus and time-course effects of kava-kava (Piper methysticum) in rats

\author{
Natalie R. Bruner
}

Thesis submitted to the Eberly College of Arts and Sciences at West Virginia University

in Partial Fulfillment of the Requirements for the Degree of

\author{
Master of Science \\ in \\ Psychology
}

Karen G. Anderson, Ph. D., Chair

Kennon A. Lattal, Ph.D.

Hawley Montgomery-Downs, Ph.D.

Department of Psychology

Morgantown, WV

2008

Keywords: drug discrimination, kava, chlordiazepoxide 


\begin{abstract}
Discriminative-stimulus and time-course effects of kava-kava (Piper methysticum) in rats
\end{abstract}

Natalie R. Bruner

Kava-kava is a widely available and used herbal medicine that is not regulated in many countries, including the United States. There are many questions concerning kava-kava's stimulus properties, potential for therapeutic use, and potential for abuse. Although there is evidence that kava may possess some anxiolytic properties, the supplement's mechanism of action and the extent to which it may serve as an alternative to pharmaceutical anxiolytics are unknown. To date, there is no research examining whether kava shares discriminative-stimulus properties with a standard pharmaceutical anxiolytic such as chlordiazepoxide (CDP). The current study compared different doses of kava in two groups of rats trained to discriminate either a high or low training dose of CDP (i.p.). In order to assess time-course effects of kava (p.o.), two tests were conducted per session at 60 (Test One) and 90 (Test Two) min following administration of kava, CDP, or $d$-amphetamine. Dose-dependent substitution of CDP was found in both training groups. $d$-Amphetamine did not substitute for either group at Test One, but marginal substitution was found in both groups at the lower doses of $d$-amphetamine during Test Two. Kava (560 mg/kg) occasioned responding indicative of partial substitution in both groups during Test One and only the low-dose group during Test Two. Several procedural variables that may have influenced the present results are discussed. 


\section{Acknowledgements}

I would first like to thank my advisor, Dr. Karen Anderson, for her guidance and support throughout the duration of this thesis project. Not only did this thesis present a valuable and challenging learning experience for me, but it also offered an excellent opportunity for intellectual and personal growth. It was Karen’s frank, encouraging, and caring attitude that created an environment conducive to success. I would also like to thank to Dr. Andy Lattal and Dr. Hawley Montgomery-Downs for serving on my thesis committee and offering their expert advice and support.

I would like to thank my lab-mates and friends James Diller and Jonathan Slezak for countless hours spent discussing this project as well as their kind words of encouragement throughout the process. I also very much appreciate those numerous undergraduate research assistants who offered their time to assist in the various stages of this project. 
Table of Contents

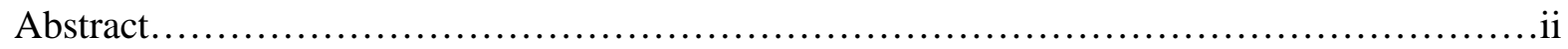

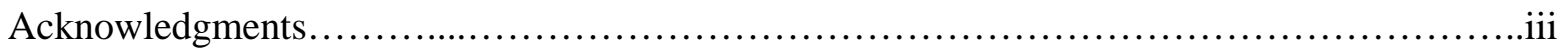

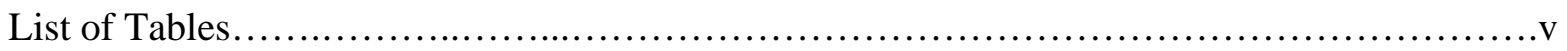

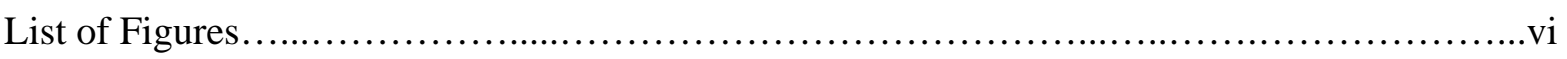

Discriminative-stimulus and time-course effects of kava-kava in rats.........................1

Literature Review...........................................................................

Statement of the Problem...................................................................

Method......................................................................... 7

Subjects...............................................................

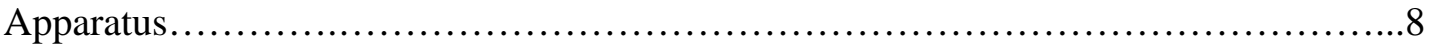

Procedure.........................................................................

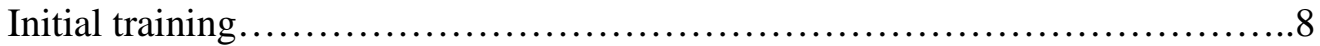

Discrimination training.............................................

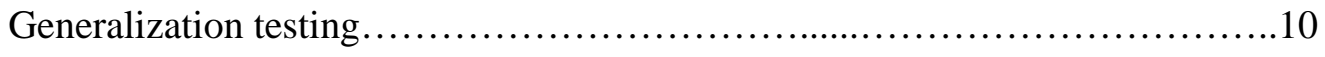

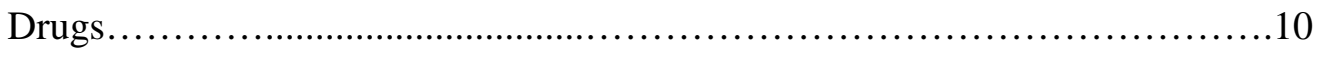

Data analyses...........................................................

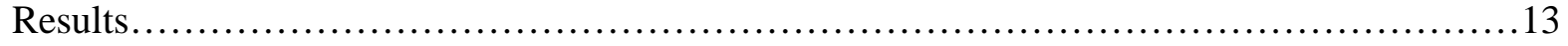

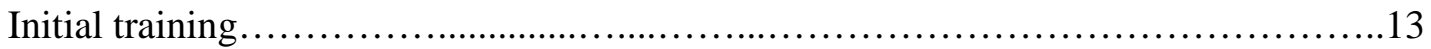

Generalization of CDP..........................................................

Generalization of saline vehicle.............................................25

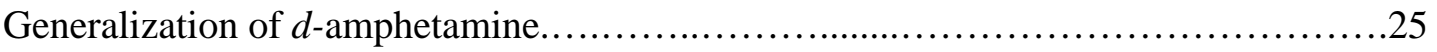

Generalization of kava............................................................26

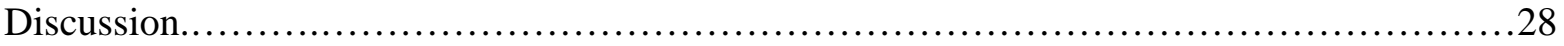

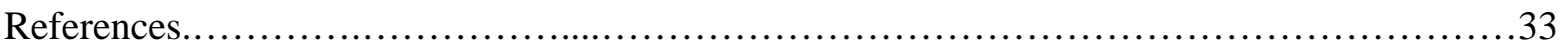

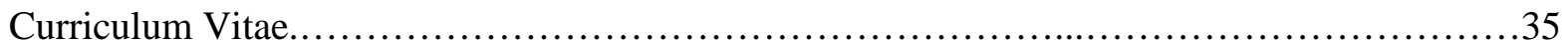


List of Tables

Table 1: Percent responding following CDP administration during Test One..........................15

Table 2: Percent responding following CDP administration during Test Two ........................16

Table 3: Percent responding following $d$-amphetamine administration..............................17

Table 4: Percent responding following kava administration .............................................18

Table 5: Responses per minute following CDP administration during Test One ...................19

Table 6: Responses per minute following CDP administration during Test Two .................20

Table 7: Responses per minute following $d$-amphetamine during Test One ........................21

Table 8: Responses per minute following kava administration during Test One ..................22 


\section{List of Figures}

Figure 1: Mean percent responding as a function of test dose..........................................23

Figure 2: Mean responses per minute as a function of test dose................................................24 
Discriminative-stimulus and time-course effects of kava-kava in rats

For hundreds of years, the people of the South Pacific have consumed the beverage kavakava (kava) for ceremonial, medicinal and social purposes (Singh, 1992). The importance of kava in the life of the South Pacific islanders is analogous to the use of alcohol in other cultures. Cultivated from the tropical shrub Piper methysticum (meaning “intoxicating pepper”), the traditional preparation consists of grinding down the thick kava root into an intoxicating murky beverage. Consuming the beverage induces a relaxed state and can help to improve social interaction (Stolerman, 1993). Kava has also been traditionally used as a natural anti-anxiety or sedative medicine.

It was not until the 1990’s that kava gained significant attention as an herbal alternative to pharmaceutical drugs for treatment of stress, anxiety, and pain. By 1994, kava had become one of the top eight herbal remedies in the \$18 million herbal remedy industry (O’Sullivan \& Lum, 2004). In 2002, several European countries banned the sales of the herb due to cases of severe hepatic toxicity in users of kava. Because it is classified as an herbal supplement, the Food and Drug Administration (FDA) of the United States does not regulate the quality of nor approve preparations of kava prior to its marketing. However, following the European ban on kava in 2002, the FDA did issue a consumer advisory pertaining to the potential harmful effects of the herb. Subsequently, several herbal remedy retailers voluntarily withdrew kava-containing items from their stores (O’Sullivan \& Lum, 2004). The potential toxic effects as well as the potential benefits of kava must be more closely examined to properly assess its usefulness as an herbal medicine. 


\section{Literature Review}

Kava-kava’s active pharmacological agents consist of 18 compounds called kavalactones. Six of these kavalactones (kavain, dihydrokavain, methysticin, dihydromethysticin, yangonin, and desmethysticin) account for about 95\% of the kava extract (Ganzera \& Khan, 1999). Smith et al. (2001) found that of the six major kavalactones tested individually in a chick social separation-stress paradigm, only dihydrokavain resulted in behavioral effects similar to those following administration of the benzodiazepine chlordiazepoxide (CDP). Feltenstein et al. (2003) reported that kava fractions containing the highest doses of dihydrokavain moderately suppressed both distress vocalizations and stress-induced analgesia. These studies suggest that some properties of kava may be similar to those of established anxiolytic drugs. More research is needed to determine whether these shared stimulus properties of kava extract are mediated by the total kavalactone content or from particular kavalactones.

Kavalactones appear to interact with $\mathrm{GABA}_{\mathrm{A}}$ receptors (Jussofie, Schmiz, \& Heimke, 1994; Singh, 2005). These are the same receptor sites that anti-anxiety drugs such as chlordiazepoxide and diazepam act upon. If kava affects the same receptors as these benzodiazepines, it may be expected to have shared stimulus properties and anxiolytic effects.

Research investigating the use of kava in human participants supports kava as an effective treatment for anxiety. Geier \& Konstantinowicz (2004) used the Hamilton Anxiety Scale as a primary dependent variable to assess self-rated subjective level of anxiety before and after kava treatment. It was found that patients had a therapeutically relevant reduction in anxiety in the kava-extract group compared to the placebo-control group. Another study with human participants supports the finding that kava is beneficial for treating anxiety symptoms in anxiety patients terminating treatment with benzodiazepines (Malsch \& Kieser, 2001). This suggests that 
kava may be an effective substitute for pharmaceutical anxiolytics such as benzodiazepines. Ernst (2006) conducted a systematic review of controlled clinical trials summarizing the anxiolytic efficacy of herbal medicines. It was reported that kava is the only herbal medicine that has been shown to have anxiolytic effects in humans.

The data concerning kava using animal models of anxiety is limited. Garrett, Basmadjian, Khan, Schaneberg, and Seale (2003) found that kava extract significantly increased changes in behavior, in a manner similar to that of drugs established as anxiolytics in humans, in two animal models of anxiety. In the mirrored-chamber avoidance paradigm, a mouse entering the mirrored chamber is surrounded by its own reflection on six sides. In the elevated-plus maze paradigm, Plexiglas surrounds the arms of one runway of the maze, and the arms of the other runway are open. Animal subjects in these assays typically spend less time in the mirrored chamber or open arms of the elevated-plus maze relative to time spent in the enclosed runway leading into the mirrored chamber or closed arms of the maze. However, following administration of a benzodiazepine, time spent in the mirrored chamber or open arms of the maze is increased. Administration of kava in these animal models of anxiety results in behavioral effects similar to those following administration of benzodiazepines. Kava extract injected intraperitoneally (i.p.) reduced both latency to enter and increased time spent in both the mirrored chamber of the mirrored-chamber avoidance assay and the open arms of the elevated-plus maze assay, compared to administration of vehicle. Rex, Morgenstern, \& Fink (2002) used an elevated-plus maze to determine orally administered (p.o.) kava-induced effects on time spent in the open arms of the maze compared to the standard anxiolytic diazepam. They reported that kava extract (120-240 $\mathrm{mg} / \mathrm{kg}$ ) and diazepam $(15 \mathrm{mg} / \mathrm{kg})$ significantly affected the time spent in the open arms and open-arm visits. Smith et al. (2001) used the chick social separation-stress paradigm to assess the 
behavioral effects of i.p. administered kava extract and isolated kavalactones. They found that kava extract (30 mg/kg) and the kavalactone dihydrokavain (30 $\mathrm{mg} / \mathrm{kg}$ ) resulted in responses comparable to that following administration of the "gold standard" anxiolytic CDP (5 mg/kg, i.p.).

Positive results in three experimental paradigms across three species of animals suggest that kava has effects on behavior similar to those produced by drugs classified as anxiolytics in clinical settings with humans. To date, there are no studies examining the discriminativestimulus properties of kava in animals. The discriminative-stimulus properties of drugs may be evaluated in a drug-discrimination procedure. The proposed study will determine if kava shares discriminative-stimulus properties similar to those of CDP using rats as subjects.

The subjective effects of drugs may be trained to serve as discriminative stimuli using a drug-discrimination procedure. In such a procedure, a discrimination is trained between a specific dose of a drug and its vehicle (e.g., saline). In drug-discrimination training, one activity (i.e., pressing a lever) is reinforced after drug administration and another activity (i.e., pressing a second lever) is reinforced in the absence of the drug (i.e., after vehicle administration). If differential responding is observed in drug-appropriate lever-pressing vs. non-drug or vehicleappropriate lever-pressing, then it may be concluded that the drug's effects are acting as a discriminative-stimulus (Branch, 1991). A common dosing schedule for drug (D) and vehicle (V) in a two-week period (Monday-Friday) is VDVDD DVDVV. For drug days, one set of contingencies is in effect (i.e., reinforcement available on the drug-appropriate lever). On vehicle (non-drug) days, a second set of contingencies is in effect (i.e., reinforcement available on the vehicle-appropriate lever). 
The drug-discrimination procedure may be used to ascertain whether another test drug shares discriminative-stimulus properties with the training drug. A discrimination between the training drug and vehicle is generally considered established when there is at least $80 \%$ correct responding on the drug-appropriate lever following administration of the training drug. Following drug training, another dose of the training drug or other drugs may be administered prior to a test session. Drugs within the same pharmacological class and novel compounds are often substituted to assess the extent to which the test drug may substitute for the training drug. To establish that responding on the drug-appropriate lever indicates shared discriminativestimulus properties with the training drug and is not an artifact of general administration of a drug, a negative control (usually a drug from another pharmacological class) is often included in testing.

Stimulus generalization may be assessed using either quantal or graded measures. Quantal indices characterize discriminative responses as all-or-none. They are measured using nominal scales and are usually averaged across subjects (Stolerman, 1993). Graded indices may allow for partial substitution of the test drugs and may be measured within and across subjects. In a graded index, the proportion of responses corresponding to one of the options (i.e., percentage of total responses on drug-appropriate lever) may be used for data analysis. To ensure that reinforcement is not serving a discriminative function, data analysis of test sessions are based on responses made prior to reinforcer delivery, or discrimination tests are conducted in extinction. Full generalization to the training drug is usually defined as at least $80 \%$ responding on the drug-appropriate lever, $21-79 \%$ as partial substitution, and less than or equal to $20 \%$ of total responses is characterized as no substitution. A dose-response function with the test drug may be compared to the dose-response function generated during the initial drug training in the 
form of a generalization gradient. Generalization gradients plot the extent to which the test drug produces a dose-effect curve similar to that of the training drug.

There are several variables that may influence generalization gradients. The dose used for the training drug to establish and maintain a discrimination influences sensitivity to the drug. A relatively low training dose will generally result in greater sensitivity to test stimuli, and doseresponse curves will subsequently be shifted to the left. Discriminations with relatively high doses are generally easier to establish (i.e., requires fewer training sessions), but may result in less sensitivity to discriminative-stimulus properties of test stimuli than that based on lower training doses. The schedule of reinforcement used in training is another important factor to consider. A schedule such as a relatively small fixed-ratio (FR) is often utilized for its capacity to engender strong stimulus control (Stolerman, 1993). Using this schedule, responses are usually emitted on a lever as a single unit, resulting in data that are more quantal in nature. A schedule such as a variable-interval (VI), which may result in responses distributed between the two choices, may result in data that are more graded in nature. However, VI schedules are characterized by a poorer capacity for engendering stimulus control. Tandem VI-FR schedules combine the advantages of these two schedules: strong stimulus control as well as fostering responding that may result in data that are graded in nature. Pharmacokinetics of the drug with respect to time-course effects is another important variable affecting the generalization gradient. The onset and duration of the drug's action will influence the point in time in which a test drug may share discriminative-stimulus properties with the training drug. Time-course effects of a drug may be assessed by conducting multiple tests in extinction (i.e., one test is conducted 60 min post-administration, and a second test is conducted 90 min post-administration). 


\section{Statement of the Problem}

Kava-kava is a widely available and used herbal medicine that is not regulated in many countries, including the United States. There are many questions concerning kava’s stimulus properties, potential for therapeutic use, and potential for abuse. Although there is evidence that kava may possess some anxiolytic properties, the extent to which it may serve as an alternative to pharmaceutical anxiolytics and the supplement's mechanism of action are unknown. To date, there is no research examining whether kava shares discriminative-stimulus properties with a standard pharmaceutical anxiolytic such as CDP. Shared discriminative-stimulus properties would suggest that kava may share other properties of pharmaceutical anxiolytics such as the mechanism of action or abuse potential. The current study compared different doses of kava in two groups of rats trained to discriminate either a high or low training dose of CDP. A positive control (multiple doses of CDP) and negative control (the stimulant $d$-amphetamine) was also incorporated in testing. Two generalization tests were conducted within each test session (Test One at $60 \mathrm{~min}$ and Test Two at 90 min post-administration) to assess time-course effects of the herb.

\section{Method}

\section{Subjects}

Sixteen experimentally naïve male Sprague-Dawley rats were used as subjects, and were approximately two months of age at the start of the experiment. Rats were housed individually with free access to water in their home cages. Temperature and humidity were maintained at constant levels and there was a reversed 12-hour light-dark cycle in effect. All sessions were conducted during the dark phase of the light-dark cycle. The subjects were fed approximately 15 
g of food one half hour following each experimental session. This schedule resulted in approximately 22 hours of food deprivation prior to the start of each session.

\section{Apparatus}

Experimental sessions were conducted in eight standard operant-conditioning chambers for rats, each enclosed in a melamine sound-attenuating cubicle (Med Associates, VT). Each chamber contained a working area of $30.5 \mathrm{~cm}$ by $24.5 \mathrm{~cm}$ by $21.0 \mathrm{~cm}$, a grid floor, and a $45-\mathrm{mg}$ pellet dispenser with a pellet receptacle centered between two retractable response levers. The levers were $11.5 \mathrm{~cm}$ apart from each other and required at least a force $0.25 \mathrm{~N}$ for a response to be recorded. The levers were $4.8 \mathrm{~cm}$ wide, protruded $1.9 \mathrm{~cm}$ into the chamber, and were elevated $8 \mathrm{~cm}$ from the grid floor. Two $28-\mathrm{V}$ stimulus lights that were $2.5 \mathrm{~cm}$ in diameter were approximately $7 \mathrm{~cm}$ above each lever. Each chamber contained a 28-V houselight on the wall opposite to wall containing the operandum. A ventilation fan circulated air and served to mask extraneous noise. Equipment was interfaced to a computer and experimental sessions and data collection was programmed and conducted with MedPC-IV (Med Associates, VT).

Procedure

Initial Training. Training sessions were conducted five days a week (Monday through Friday) at approximately the same time each day. The subjects were trained to lever press using a free-operant acquisition procedure (cf: van Haaren, 1992; Anderson \& van Haaren, 1999). Each rat was placed in a darkened experimental chamber and the ventilation fan was turned on. Ten min later, the houselight and stimulus lights above both levers were illuminated. Food was delivered according to a conjoint FR 1 variable-time (VT) 60-s schedule. Values for the VT were obtained using a Fleshler-Hoffman sequence generator (Fleshler-Hoffman, 1962). Rats received one food pellet either after a lever press or after an average of $60 \mathrm{~s}$ has elapsed. If any subjects 
failed to acquire the response following the lever-press training procedure, the lever-press was shaped through reinforcement of successive approximations. When subjects were obtaining most food pellets via the lever press, subjects then completed an FR 1 schedule that alternated between the left and right levers after the delivery of five food pellets on each lever for 40 food pellets total. The ratio was increased gradually over consecutive sessions until an FR 10 was reached. The next phase of lever press acquisition training consisted of a VI 15-s schedule. After responding reliably on the VI 15-s schedule, subjects were then exposed to a VI 30-s schedule. The subjects entered the next phase of the experiment after responding reliably on a VI 30-s schedule.

Discrimination training. The subjects were divided into two groups of eight rats. Sessions were conducted five, and then seven days a week. Initially, training began with a relatively low training dose of CDP ( $3.0 \mathrm{mg} / \mathrm{kg}$ ) for one group. The other group was exposed to a higher training dose of CDP $(17.0 \mathrm{mg} / \mathrm{kg})$. The training doses were subsequently adjusted in order to facilitate discrimination (i.e., the low training dose was increased to CDP $5.6 \mathrm{mg} / \mathrm{kg}$ ), or to decrease response suppression (i.e., the high training dose was decreased to CDP $13.0 \mathrm{mg} / \mathrm{kg}$ ). One of the subjects in the high-dose training group was changed to the lower training dose after failing to respond following drug administration. The drug (D) or saline vehicle (V) was administered via i.p. injection prior to each daily session in the following order for each twoweek period (Monday-Friday): VDVDD DVDVV. Following the injection, the subject was placed immediately in the darkened experimental chamber and the ventilation fan was turned on. After a period of $15 \mathrm{~min}$, the houselight and both lever lights were illuminated, and both levers were extended into the chamber. Food pellet presentation followed responses on the vehicle- or drug-appropriate lever according to a tandem VI 30-s FR 10 (TAND (VI 30-s, FR 10)) schedule 
of reinforcement. For one half of each group, fulfilling the required responses on the left lever resulted in food pellet delivery following injection of saline, and responses on the right lever resulted in food pellet delivery following injection of CDP. For the other half of each group, the levers were counterbalanced such that reinforced responses were on the left lever following CDP injection and the right lever following saline injection. Responses on the other lever were counted but had no other scheduled consequences (extinction; incorrect lever). Sessions were terminated following the presentation of 40 food pellets or $30 \mathrm{~min}$, whichever occurred first. After 150 sessions, only one subject had met the original training criteria. Therefore, the dosing schedule was slightly modified to constitute a 24-day period (seven days a week): VDVDDDVDVDVV DVDVVVDVDVDD. In addition, the VI component of the training schedule was removed, and for the rest of the experiment an FR 10 schedule of reinforcement was in effect.

Generalization testing. Generalization testing began after the subjects emitted at least $80 \%$ correct lever presses before the delivery of the first food pellet for five consecutive sessions. Rats that did not successfully complete discrimination training were not included in the testing phase (i.e., three rats in the low-dose group). Generalization tests were conducted on Tuesdays and Fridays, once following a vehicle injection session and once following a drug injection session. Each dose of CDP, kava, and $d$-amphetamine was tested at least twice. The subjects were injected (i.p.) and immediately placed in the darkened experimental chamber. After 15 min, Test One began. Both levers were extended into the chamber and the houselight and both lever lights were illuminated for five min or until completion of the response requirement for FR 10. After completing the required responses, instead of delivery of a food pellet, both levers were retracted, and the houselight and stimulus lights were darkened until the beginning of Test Two. 
During the interval between tests, all lights remained extinguished and the levers remained retracted from the chamber. If the response requirement was not met within five min of the onset of the test, the experimental chamber was darkened and the levers were retracted until Test Two began. Thirty min following drug injection, a second generalization test commenced. This test was identical to the first and the session was terminated upon its completion. Some generalization tests were conducted using an i.p. route of administration for chlordiazepoxide, saline, kava extract, and kava vehicle (see Drugs for vehicle composition).

After several generalization tests following i.p. administration of kava, it was evident that kava was not generalizing to the training stimuli, so these data are not presented. In order to rule out drug absorption issues due to poor solubility of the compound, a change was made. All drugs were administered orally via gastric gavage (p.o.) on test days. Subjects were administered test drugs 60 min prior to the start of Test One and placed back into their home cage. Forty-five min following drug administration, subjects were placed into the operant-conditioning chamber and the ventilation fan was turned on. Fifteen min later, Test One began. Test Two began 90 min after drug administration. Contingencies during each test were the same as described above. Generalization tests were conducted for CDP (1.0-13.0 mg/kg), $d$-amphetamine (0.3-3.0 mg/kg), saline, kava vehicle, and kava extract (300-560 mg/kg). Most subjects received at least two determinations of each dose. However, due to time constraints, some subjects experienced doses of kava or $d$-amphetamine only once. In some instances, drug doses (e.g., kava $560 \mathrm{mg} / \mathrm{kg}, d$ amphetamine $3.0 \mathrm{mg} / \mathrm{kg}$ ) suppressed responding almost completely. The data from these determinations are excluded from data analyses.

Drugs. Chlordiazepoxide hydrochloride (Sigma-Aldrich, St. Louis, MO) was dissolved in 0.9\% saline vehicle and administered 15 min prior to training (i.p.) and 60 min prior to testing 
(p.o.). Kava extract was generously supplied by the National Center for Natural Products

Research at the University of Mississippi (Oxford, MS). The extract was dissolved in the kava vehicle (91\% distilled water, 4\% ethanol, 4\% Tween 80, and 1\% dimethyl sulfoxide) and administered 60 min prior to testing (p.o.). Kavalactones comprised 84\% of the kava extract. The kavalactone content was comprised of 49\% kavain, 18.6\% dihydrokavain, $9.8 \%$ methysticin, 8.4\% dihydromethysticin, 5.8\% yangonin, and 4.8\% desmethoxyangonin. $d$-Amphetamine (Sigma-Aldrich Company, St. Louis, MO) was dissolved in 0.9\% saline and administered 60 min prior to testing (p.o.).

Data analysis. The percentage of correct (injection-appropriate) lever presses in training was determined by dividing the number of responses made on the injection-appropriate lever by the number of total responses made on both levers preceding the delivery of the first food pellet. Response rate (responses per min) on the injection-appropriate lever in training was determined by dividing the total number of lever presses on the injection-appropriate lever by the duration (min) of each session. Training data were represented graphically in which the percent choice of injection-appropriate lever was plotted as a function of injection type (drug or saline).

Calculations were the same for the generalization tests, except data collection ended when the required responses were made or when the session timed out. Only data following oral administration of the test drugs are presented. In testing, only percentage of total responses and response rate on the CDP-appropriate were calculated and plotted. Test data were not included if subjects failed to fulfill the schedule requirement (i.e., ten responses were not emitted on a single lever). In the case where partial substitution of a test compound was found, the percentage of total responses emitted on the CDP-appropriate lever was tested for significance with a 3-way repeated measures ANOVA. Occasionally, subjects did not receive a test dose or failed to 
respond following a test dose. In these cases, data were interpolated from the group mean for that dose. In the case that main effects (training group, test time, drug dose) were found, t-tests were conducted as post-hoc analyses. The median effective dose $\left(E D_{50}\right)$ for each drug was calculated by log-linear interpolation of the descending portion of the dose-effect curve. For all statistical tests, $\mathrm{p}<0.05$ was considered to be significant. The percentage of responses emitted greater than or equal to $80 \%$ on the CDP lever was considered to be full substitution, $21-79 \%$ partial substitution, and less than or equal to $20 \%$ no substitution.

\section{Results}

Discrimination Training. The CDP discrimination required an average of 40 training sessions on FR 10 for the low-dose group (range 25-62 sessions) and an average of 32 sessions (range 23-49 sessions) for the high-dose group. For the last ten sessions of the training phase, the mean percent correct lever responding was 93.7\% (range 86.6-100\%) for the low-dose training group and 95.9\% (range 88.6-100\%) for the high-dose training group. The mean response rate on the stimulus-appropriate lever was $64.5 \mathrm{rsp} / \mathrm{min}$ (range 56.6-82.0 rsp/min) and $62.3 \mathrm{rsp} / \mathrm{min}$ (range 52.9-73.4 rsp/min) for the low-dose and high-dose group, respectively. Subsequent t-tests revealed no significant differences between groups for mean percentage of total responses or response rate on the stimulus-appropriate lever.

Generalization of CDP. In general, full substitution of CDP was found at doses equivalent to and above that of the training dose for both groups in Test One (Figure 1). In both groups, doses smaller than the training dose only partially substituted for the training dose. The percentage of total responses emitted on the CDP-appropriate lever was functionally related to the dose of CDP administered. The lower $\mathrm{ED}_{50}$ value in the low-dose group (especially in Test One) suggests greater sensitivity to the discriminative-stimulus effects of CDP administration. 
During Test One, the $\mathrm{ED}_{50} \mathrm{~s}$ for the low-dose and high-dose groups were CDP $2.9 \mathrm{mg} / \mathrm{kg}$ and CDP $5.9 \mathrm{mg} / \mathrm{kg}$, respectively. However, subsequent t-tests did not reveal any significant differences in $\mathrm{ED}_{50}$ values between groups. Individual data during Test One following administration (p.o.) of CDP are presented in Table 1.

On average, full substitution of the training dose was found in the high-dose group, but only partial substitution was found in the low-dose group during Test Two (Figure 1). Three of the rats in the low- training group and only one in the high-dose group emitted at least $80 \%$ of total responses on the CDP lever during Test Two following administration of the training dose. In both groups, the average percentage of total responses emitted on the CDP-appropriate lever was functionally related to CDP dose, such that the average percentage increased as the dose size increased. The $\mathrm{ED}_{50} \mathrm{~s}$ for the low-dose and high-dose groups were CDP $3.5 \mathrm{mg} / \mathrm{kg}$ and CDP 3.3 $\mathrm{mg} / \mathrm{kg}$, respectively. Subsequent t-tests did not reveal any significant differences in $\mathrm{ED}_{50}$ values between subjects. Individual data during Test Two following CDP administration are presented in Table 2.

Response rates on the CDP-appropriate lever were also calculated during both tests. For both groups, the mean response rate on the CDP-appropriate lever was functionally related to the dose of CDP administered (Figure 2) during Test One. The response rate on the CDP-appropriate lever systematically increased as the dose of CDP increased. During Test One, the average response rate on the CDP-appropriate lever for the low-dose group (52.9 rsp/min) was lower than that of the high-dose group (77.2 rsp/min) following administration of the training dose. Individual data for response rate on the CDP-appropriate lever in Test One are presented in Table 5. 
Table 1

Mean Percent Responding, S.E.M, and Number of Determinations for Each dose (SEM, determinations) on CDP-appropriate Lever Following CDP Administration (mg/kg, p.o.) in Individual Subjects During Test One

\begin{tabular}{|c|c|c|c|c|c|c|}
\hline \multirow[b]{2}{*}{ Rat ID } & \multirow{2}{*}{$\begin{array}{c}\text { Training } \\
\text { Dose }\end{array}$} & \multicolumn{5}{|c|}{ Test One } \\
\hline & & CDP 1.0 & CDP 3.0 & CDP 5.6 & CDP 10.0 & CDP 13.0 \\
\hline S60-2 & Low (5.6) & $71.1(9.7,3)$ & $9.1(0.0,2)$ & $75.0(22.1,4)$ & - & - \\
\hline S60-4 & Low (5.6) & $4.5(4.5,2)$ & $44.0(27.4,2)$ & $87.1(3.8,2)$ & $95.5(4.5,2)$ & - \\
\hline S60-5 & Low (5.6) & $0.0(0.0,2)$ & $96.9(3.0,3)$ & $95.5(4.5,2)$ & - & - \\
\hline S60-8 & Low (5.6) & $16.7(16.7,2)$ & $91.7(8.3,2)$ & $100.0(0.0,2)$ & $100.0(0.0,2)$ & - \\
\hline S70-5 & Low (5.6) & $33.3(33.3,3)$ & $50.0(50.0,2)$ & $100.0(0.0,2)$ & $100.0(0.0,1)$ & - \\
\hline S70-7 & Low (5.6) & $11.5(11.5,2)$ & $66.7(33.3,3)$ & $89.3(6.7,3)$ & $100.0(0.0,1)$ & - \\
\hline & p mean & $27.3(9.8)$ & $62.9(11.8)$ & $88.9(6.0)$ & $98.5(1.5)$ & - \\
\hline S70-3 & High (13.0) & $33.3(33.3,3)$ & $0.0(0.0,2)$ & $33.3(33.3,3)$ & - & $100.0(100.0,3)$ \\
\hline S70-4 & High (13.0) & - & $0.0(0.0,2)$ & $4.5(4.5,2)$ & - & $81.4(9.5,3)$ \\
\hline S60-7 & High (13.0) & $0.0(0.0,1)$ & $27.3(24.3,4)$ & $100.0(0.0,2)$ & - & $100.0(0.0,3)$ \\
\hline & mean & $25.0(25.0)$ & $13.6(12.4)$ & $44.2(19.8)$ & - & $93.8(4.1)$ \\
\hline
\end{tabular}


Table 2

Mean Percent Responding, S.E.M, and Number of Determinations for Each dose (SEM, determinations) on CDP-appropriate Lever Following CDP Administration (mg/kg, p.o.) in Individual Subjects During Test Two

\begin{tabular}{|c|c|c|c|c|c|c|}
\hline \multirow[b]{2}{*}{ Rat ID } & \multicolumn{2}{|l|}{ Training } & \multicolumn{3}{|c|}{ Test Two } & \multirow[b]{2}{*}{ CDP 13.0} \\
\hline & Dose & CDP 1.0 & CDP 3.0 & CDP 5.6 & CDP 10.0 & \\
\hline S60-2 & Low (5.6) & $50.5(24.8,3)$ & $26.8(17.7,2)$ & $55.0(26.0,4)$ & - & - \\
\hline S60-4 & Low (5.6) & $0.0(0.0,2)$ & $62.5(19.7,2)$ & $100.0(0.0,2)$ & $37.9(14.8,2)$ & - \\
\hline S60-5 & Low (5.6) & $57.0(33.9,2)$ & $69.7(30.3,3)$ & $100.0(0.0,2)$ & - & - \\
\hline S60-8 & Low (5.6) & $0.0(0.0,2)$ & $0.0(0.0,2)$ & $100.0(0.0,2)$ & $68.8(31.2,2)$ & - \\
\hline S70-5 & Low (5.6) & $66.7(33.3,3)$ & $50.0(50.0,2)$ & $100.0(0.0,2)$ & $100.0(0.0,1)$ & - \\
\hline S70-7 & Low (5.6) & $35.7(35.7,2)$ & $64.1(27.9,3)$ & $57.1(29.7,3)$ & $100.0(0.0,1)$ & - \\
\hline \multicolumn{2}{|c|}{ Group mean } & 38.4 (11.6) & $45.8(11.6)$ & $67.0(11.7)$ & $68.9(14.4)$ & - \\
\hline S70-3 & High (13.0) & $0.0(0.0,3)$ & $100.0(0.0,2)$ & $72.2(27.8,3)$ & - & $100.0(0.0,3)$ \\
\hline S70-4 & High (13.0) & - & $0.0(0.0,2)$ & $0.0(0.0,2)$ & - & $71.3(24.2,3)$ \\
\hline S60-7 & High (13.0) & $9.1(0.0,1)$ & $0.0(0.0,4)$ & $100.0,(0.0,2)$ & - & $69.7(30.3,3)$ \\
\hline & nean & $2.3(2.3)$ & $25.0(16.4)$ & 59.5 (19.2) & - & $80.3(12.2)$ \\
\hline
\end{tabular}


Table 3

Mean Percent Responding, S.E.M, and Number of Determinations for Each Dose (SEM, determinations) on CDP-appropriate Lever

Following d-Amphetamine Administration (mg/kg, p.o.) in Individual Subjects

\begin{tabular}{|c|c|c|c|c|c|c|c|c|c|}
\hline \multirow[b]{2}{*}{ Rat ID } & \multirow{2}{*}{$\begin{array}{c}\text { Training } \\
\text { Dose }\end{array}$} & \multicolumn{4}{|c|}{ Test One } & \multicolumn{4}{|c|}{ Test Two } \\
\hline & & Saline & d-amp 0.3 & d-amp 1.0 & d-amp 3.0 & Saline & d-amp 0.3 & d-amp 1.0 & d-amp 3.0 \\
\hline S60-2 & Low (5.6) & $18.0(3.3,4)$ & $16.7(0.0,1)$ & $9.1(0.0,1)$ & - & $6.4(4.0,4)$ & $0.0(0.0,1)$ & $55.6(0.0,1)$ & - \\
\hline S60-4 & Low (5.6) & $0.0(0.0,5)$ & - & $8.3(8.3,2)$ & $11.1(11.1,2)$ & $31.8(20.5,5)$ & - & $8.3(8.3,2)$ & $0.0(0.0,2)$ \\
\hline S60-5 & Low (5.6) & $2.3(2.3,4)$ & $0.0(0.0,3)$ & $0.0(0.0,3)$ & - & $2.3(2.3,4)$ & $31.9(18.1,3)$ & $30.3(30.3,3)$ & - \\
\hline S60-8 & Low (5.6) & $0.0(0.0,3)$ & - & $0.0(0.0,2)$ & $0.0(0.0,2)$ & $0.0(0.0,3)$ & - & $0.0(0.0,2)$ & $0.0(0.0,2)$ \\
\hline S70-5 & Low (5.6) & $0.0(0.0,2)$ & $0.0(0.0,3)$ & & - & $50.0(50.0,2)$ & $30.3(30.3,3)$ & $0.0(0.0,2)$ & - \\
\hline S70-7 & Low (5.6) & $0.0(0.0,4)$ & $23.8(23.8,4)$ & $43.1(21.6,3)$ & - & $9.4(9.4,4)$ & $69.8(4.6,4)$ & $55.6(27.8,3)$ & - \\
\hline \multicolumn{2}{|c|}{ Group mean } & 3.7 (1.6) & $16.3(9.9)$ & $11.9(6.6)$ & $6.7(6.7)$ & $13.8(6.1)$ & $42.4(11.0)$ & $25.4(10.5)$ & $0.0(0.0)$ \\
\hline S70-3 & High (13.0) & $0.0(0.0,3)$ & $0.0(0.0,3)$ & $0.0(0.0,2)$ & - & $0.0(0.0,3)$ & $38.9(30.9,3)$ & $0.0(0.0,2)$ & - \\
\hline S70-4 & High (13.0) & $0.0(0.0,4)$ & $0.0(0.0,2)$ & $0.0(0.0,2)$ & - & $12.6(8.4,4)$ & $18.8(9.7,2)$ & $0.0(0.0,2)$ & - \\
\hline S60-7 & High (13.0) & $0.0(0.0,4)$ & - & $0.0(0.0,2)$ & $0.0(0.0,2)$ & $0.0(0.0,4)$ & - & $0.0(0.0,2)$ & $0.0(0.0,2)$ \\
\hline \multicolumn{2}{|c|}{ Group mean } & $0.0(0.0)$ & $0.0(0.0)$ & $0.0(0.0)$ & $0.0(0.0)$ & $3.4(2.6)$ & 30.9 (17.9) & $0.0(0.0)$ & $0.0(0.0)$ \\
\hline
\end{tabular}


Table 4

Mean Percent Responding, SEM, and Number of Determinations for Each Dose (SEM, determinations) on CDP-appropriate Lever Following Kava Administration (mg/kg, p.o.) in Individual Subjects

\begin{tabular}{|c|c|c|c|c|c|c|c|}
\hline \multirow[b]{2}{*}{ Rat ID } & \multicolumn{2}{|l|}{ Training } & \multicolumn{2}{|l|}{ Test One } & \multicolumn{3}{|c|}{ Test Two } \\
\hline & Dose & kava vehicle & kava 300 & kava 560 & kava vehicle & kava 300 & kava 560 \\
\hline S60-2 & Low (5.6) & $23.1(0.0,1)$ & $23.1(0.0,1)$ & $33.9(24.9,2)$ & $9.1(0.0,1)$ & $9.1(0.0,1)$ & $54.5(45.5,2)$ \\
\hline S60-4 & Low (5.6) & $4.5(2.5,2)$ & $0.0(0.0,2)$ & $33.3(28.9,3)$ & $4.5(4.5,2)$ & $19.9(3.2,2)$ & $8.6(4.8,3)$ \\
\hline S60-5 & Low (5.6) & $33.3(33.3,3)$ & $13.7(13.7,3)$ & $95.5(4.5,2)$ & $30.3(30.3,3)$ & $24.8(12.6,3)$ & $4.5(4.5,2)$ \\
\hline S60-8 & Low (5.6) & $10.3(10.3,4)$ & $0.0(0.0,2)$ & $0.0(0.0,2)$ & $0.0(0.0,4)$ & $0.0(0.0,2)$ & $0.0(0.0,2)$ \\
\hline S70-5 & Low (5.6) & $0.0(0.0,1)$ & $0.0(0.0,2)$ & $0.0(0.0,3)$ & $9.1(0.0,1)$ & $8.3(8.3,2)$ & $66.7(33.3,3)$ \\
\hline S70-7 & Low (5.6) & $0.0(0.0,2)$ & $0.0(0.0,2)$ & $91.7(18.3,2)$ & $0.0(0.0,2)$ & $28.2(5.1,2)$ & $69.0(2.4,2)$ \\
\hline & p mean & $15.8(9.3)$ & $5.4(3.8)$ & $38.7(12.0)$ & 7.8 (3.8) & $17.7(7.4)$ & 34.4 (11.4) \\
\hline S60-7 & High (13.0) & $0.0(0.0,2)$ & $0.0(0.0,3)$ & $0.0(0.0,3)$ & $0.0(0.0,2)$ & $5.6(5.6,3)$ & $9.5(9.5,3)$ \\
\hline S70-3 & High (13.0) & $0.0(0.0,1)$ & $4.5(4.5,3)$ & $30.3(30.3,1)$ & $0.0(0.0,1)$ & $33.3(33.3,3)$ & $0.0(0.0,1)$ \\
\hline S70-4 & High (13.0) & $0.0(0.0,1)$ & $11.1(11.1,2)$ & $42.9(29.7,3)$ & $0.0(0.0,1)$ & $0.0(0.0,2)$ & $30.3(30.3,3)$ \\
\hline & p mean & $0.0(0.0)$ & $5.3(4.2)$ & 31.4 (17.0) & $0.0(0.0)$ & $14.6(12.4)$ & $17.1(12.9)$ \\
\hline
\end{tabular}


Table 5

Mean Responses per Minute, SEM, and Number of Determinations for Each Dose (SEM, determinations) on CDP-appropriate Lever Following CDP Administration (mg/kg, p.o.) in Individual Subjects During Test One

\begin{tabular}{|c|c|c|c|c|c|c|}
\hline \multirow[b]{2}{*}{ Rat ID } & \multicolumn{2}{|l|}{ Training } & \multicolumn{3}{|c|}{ Test One } & \multirow[b]{2}{*}{ CDP 13.0} \\
\hline & Dose & CDP 1.0 & CDP 3.0 & CDP 5.6 & CDP 10.0 & \\
\hline S60-2 & Low (5.6) & $34.4(10.2,3)$ & $4.3(0.3,2)$ & $48.4(15.4,4)$ & - & - \\
\hline S60-4 & Low (5.6) & $2.8(2.8,2)$ & $18.7(8.7,2)$ & $66.0(19.8,2)$ & $76.2(9.5,2)$ & - \\
\hline S60-5 & Low (5.6) & $0.0(0.0,2)$ & $44.8(8.3,3)$ & $38.1(8.1,2)$ & - & - \\
\hline S60-8 & Low (5.6) & $11.6(11.6,2)$ & $59.7(40.3,2)$ & $75(0.0,2)$ & $85(35.0,2)$ & - \\
\hline S70-5 & Low (5.6) & $13.3(13.3,3)$ & $16.7(16.7,2)$ & $70.2(15.6,2)$ & $100.0(0.0,1)$ & - \\
\hline S70-7 & Low (5.6) & $3.8(3.8,2)$ & $25.9(13.6,3)$ & $33.7(8.2,3)$ & $50.0(0.0,1)$ & - \\
\hline \multicolumn{2}{|r|}{ Group mean } & $12.8(4.7)$ & $29.4(7.4)$ & $52.9(6.2)$ & 78.8 (11.5) & - \\
\hline S70-3 & High (13.0) & $37.5(37.5,3)$ & $0.0(0.0,2)$ & $20(39.2,3)$ & - & $19.2(3.4,3)$ \\
\hline S70-4 & High (13.0) & - & $0.0(0.0,2)$ & $5.0(5.0,2)$ & - & $75.8(34.7,3)$ \\
\hline S60-7 & High (13.0) & $0.0(0.0,1)$ & $28.0(24.2,4)$ & $85.7(0.0,2)$ & - & $106.7(6.7,3)$ \\
\hline & Group mean & $18.8(18.8)$ & $14.0(12.4)$ & 34.5 (15.5) & - & $77.2(13.2)$ \\
\hline
\end{tabular}


Table 6

Mean Responses per Minute, SEM, and Number of Determinations for Each Dose (SEM, determinations) on CDP-appropriate Lever Following CDP Administration (mg/kg, p.o.) in Individual Subjects During Test One

\begin{tabular}{|c|c|c|c|c|c|c|}
\hline \multirow[b]{2}{*}{ Rat ID } & \multicolumn{2}{|l|}{ Training } & \multicolumn{3}{|c|}{ Test Two } & \multirow[b]{2}{*}{ CDP 13.0} \\
\hline & Dose & CDP 1.0 & CDP 3.0 & CDP 5.6 & CDP 10.0 & \\
\hline S60-2 & Low (5.6) & $16.9(10.4,3)$ & $11.4(7.9,2)$ & $24.0(12.0,4)$ & - & - \\
\hline S60-4 & Low (5.6) & $0.0(0.0,2)$ & $16.5(12.1,2)$ & $44.9(9.6,2)$ & $5.9(0.3,2)$ & - \\
\hline S60-5 & Low (5.6) & $17.7(13.9,2)$ & $16.5(7.3,3)$ & $34.6(3.0,2)$ & - & - \\
\hline S60-8 & Low (5.6) & $0.0(0.0,2)$ & $0.0(0.0,2)$ & $0.0(0.0,2)$ & $31.0(25.3,2)$ & - \\
\hline S70-5 & Low (5.6) & $29.3(5.5,3)$ & $13.1(13.1,2)$ & $42.6(7.4,2)$ & $60.0(0.0,1)$ & - \\
\hline S70-7 & Low (5.6) & $15.0(15.0,2)$ & $18.5(10.2,3)$ & $14.3(8.3,3)$ & $18.2(0.0,1)$ & - \\
\hline \multicolumn{2}{|c|}{ Group mean } & $14.6(4.2)$ & $12.4(3.3)$ & $25.5(5.2)$ & $25.3(10.6)$ & - \\
\hline S70-3 & High (13.0) & $0.0(0.0,3)$ & $30.0(0.0,2)$ & $26.1(12.9,3)$ & - & $40.5(3.2,3)$ \\
\hline S70-4 & High (13.0) & - & $0.0(0.0,2)$ & $0.0(0.0,2)$ & - & $25.6(4.0,3)$ \\
\hline S60-7 & High (13.0) & $5.5(0.0,1)$ & $21.4(21.4,4)$ & $70.2(15.6,2)$ & - & $28.8(24.1,3)$ \\
\hline \multicolumn{2}{|c|}{ Group mean } & $1.4(1.4)$ & $18.2(10.8)$ & 31.2 (12.5) & - & $31.0(7.5)$ \\
\hline
\end{tabular}


Table 7

Mean Responses per Minute, SEM, and Number of Determinations for Each Dose (SEM, determinations) on CDP-appropriate Lever Following d-amphetamine Administration (mg/kg, p.o.) in Individual Subjects

\begin{tabular}{|c|c|c|c|c|c|c|c|c|c|}
\hline \multirow[b]{2}{*}{ Rat ID } & \multirow{2}{*}{$\begin{array}{c}\text { Training } \\
\text { Dose }\end{array}$} & \multicolumn{4}{|c|}{ Test One } & \multicolumn{4}{|c|}{ Test Two } \\
\hline & & Saline & $d$-amp 0.3 & $d$-amp 1.0 & $d$-amp 3.0 & Saline & $d$-amp 0.3 & $d$-amp 1.0 & $d$-amp 3.0 \\
\hline S60-2 & Low (5.6) & $6.8(1.4,4)$ & $1.8(0.0,1)$ & $4.3(0.0,1)$ & - & $0.1(0.7,4)$ & $0.0(0.0,1)$ & 25.0 & - \\
\hline S60-4 & Low (5.6) & $0.0(0.0,5)$ & - & $2.9(2.9,2)$ & $1.0(1.0,2)$ & $10.2(7.0,5)$ & - & $2.1(2.1)$ & $0.0(0.0,2)$ \\
\hline S60-5 & Low (5.6) & $0.6(0.6,4)$ & $0.0(0.0,3)$ & $0.0(0.0,3)$ & - & $0.4(0.4,4)$ & $8.3(5.5,3)$ & $3.0(3.0)$ & - \\
\hline S60-8 & Low (5.6) & $0.0(0.0,3)$ & - & $0.0(0.0,2)$ & $0.0(0.0,2)$ & $0.0(0.0,3)$ & - & $0.0(0.0,2)$ & $0.0(0.0,2)$ \\
\hline S70-5 & Low (5.6) & $0.0(0.0,2)$ & $0.0(0.0,3)$ & $0.0(0.0,2)$ & - & $7.2(7.2,2)$ & $8.7(8.7,3)$ & $0.0(0.0,2)$ & - \\
\hline S70-7 & Low (5.6) & $0.0(0.0,4)$ & $14.4(8.7,4)$ & $8.8(6.8,3)$ & - & $1.6(1.6,4)$ & $21.0(3.8,4)$ & $17.9(9.0)$ & - \\
\hline \multicolumn{2}{|c|}{ Group mean } & $1.3(0.6)$ & $5.4(3.6)$ & $2.8(1.7)$ & $0.6(0.6)$ & 3.5 (1.8) & $12.3(3.5)$ & 7.1 (3.1) & $0.0(0.0)$ \\
\hline S70-3 & High (13.0) & $0.0(0.0,3)$ & $0.0(0.0,3)$ & $0.0(0.0,2)$ & - & $0.0(0.0,3)$ & $10.4(9.1,3)$ & $0.0(0.0,2)$ & - \\
\hline S70-4 & High (13.0) & $0.0(0.0,4)$ & $0.0(0.0,2)$ & $0.0(0.0,2)$ & - & $0.0(0.0,4)$ & 11.8 (4.3), 2 & $0.0(0.0,2)$ & - \\
\hline S60-7 & High (13.0) & $0.0(0.0,4)$ & - & $0.0(0.0,2)$ & $0.0(0.0,2)$ & $0.0(0.0,4)$ & - & $0.0(0.0,2)$ & $0.0(0.0,2)$ \\
\hline \multicolumn{2}{|c|}{ Group mean } & $0.0(0.0)$ & $0.0(0.0)$ & $0.0(0.0)$ & $0.0(0.0)$ & $0.0(0.0)$ & $10.9(5.2)$ & $0.0(0.0)$ & $0.0(0.0)$ \\
\hline
\end{tabular}


Table 8

Mean Responses per Minute, SEM, and Number of Determinations for Each Dose (SEM, determinations) on CDP-appropriate Lever Following Kava Administration (mg/kg, p.o.) in Individual Subjects

\begin{tabular}{|c|c|c|c|c|c|c|c|}
\hline \multirow[b]{2}{*}{ Rat ID } & \multirow{2}{*}{$\begin{array}{c}\text { Training } \\
\text { Dose }\end{array}$} & \multicolumn{3}{|c|}{ Test One } & \multicolumn{3}{|c|}{ Test Two } \\
\hline & & kava vehicle & kava 300 & kava 560 & kava vehicle & kava 300 & kava 560 \\
\hline S60-2 & Low (5.6) & $9.0(0.0,1)$ & $6.0(0.0,1)$ & $13.7(9.4,2)$ & $2.1(0.0,1)$ & $2.1(0.0,1)$ & $30.7(29.4,2)$ \\
\hline S60-4 & Low (5.6) & $2.5(2.5,2)$ & $0.0(0.0,2)$ & $16.4(14.9,3)$ & $0.4(0.4,2)$ & $1.3(0.7,2)$ & $0.9(0.6,3)$ \\
\hline S60-5 & Low (5.6) & $13.7(13.7,3)$ & $1.6(1.6,3)$ & $23.9(7.7,2)$ & $11.4(1.7,3)$ & $4.8(4.8,3)$ & $0.7(0.7,2)$ \\
\hline S60-8 & Low (5.6) & $2.9(2.9,4)$ & $0.0(0.0,2)$ & $0.0(0.0,2)$ & $0.0(0.0,4)$ & $0.0(0.0,2)$ & $0.0(0.0,2)$ \\
\hline S70-5 & Low (5.6) & $0.0(0.0,1)$ & $0.0(0.0,2)$ & $0.0(0.0,2)$ & $1.3(0.0,1)$ & $2.7(2.7,2)$ & $23.9(12.2,3)$ \\
\hline S70-7 & Low (5.6) & $0.0(0.0,2)$ & $0.0(0.0,2)$ & $33.0(9.9,3)$ & $0.0(0.0,2)$ & $7.8(2.5,2)$ & $9.9(0.8,2)$ \\
\hline \multicolumn{2}{|c|}{ Group mean } & $4.4(2.4)$ & $0.9(0.6)$ & $13.6(4.5)$ & $2.2(1.3)$ & $3.3(1.4)$ & $11.2(5.1)$ \\
\hline S60-7 & High (13.0) & $0.0(0.0,2)$ & $0.0(0.0,3)$ & $0.0(0.0,3)$ & $0.0(0.0,2)$ & $5.0(5.0,3)$ & $4.0(4.0,3)$ \\
\hline S70-3 & High (13.0) & $0.0(0.0,1)$ & $0.0(0.0,2)$ & $0.0(0.0,3)$ & $0.0(0.0,1)$ & $6.9(6.9,2)$ & $0.0(0.0,3)$ \\
\hline S70-4 & High (13.0) & $0.0(0.0,1)$ & $10.0(10.0,3)$ & $30.0(17.3,2)$ & $0.0(0.0,1)$ & $0.0(0.0,3)$ & $22.2(22.2,2)$ \\
\hline \multicolumn{2}{|c|}{ Group mean } & $0.0(0.0)$ & $4.7(3.7)$ & $22.4(11.4)$ & $0.0(0.0)$ & $4.5(3.0)$ & $11.2(9.4)$ \\
\hline
\end{tabular}


Figure 1.
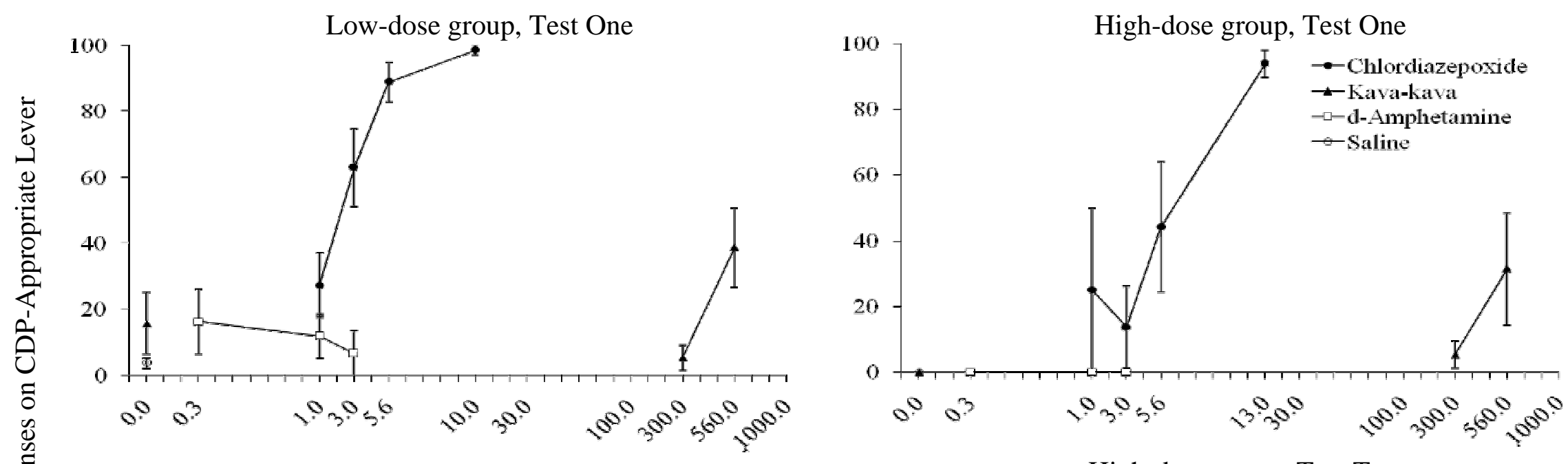

Low-dose group, Test Two

High-dose group, Test Two
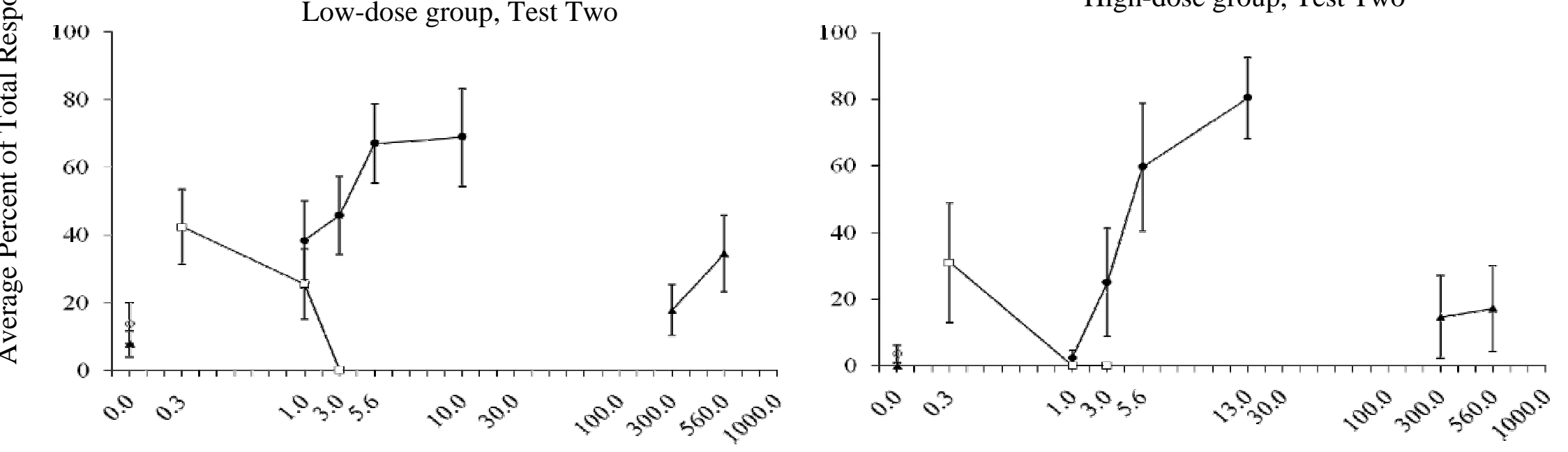

Drug Dose $(\mathrm{mg} / \mathrm{kg})$

Figure 1. Mean percent and SEM of total responses emitted on the CDP-appropriate lever for each of the test doses of CDP, $d$ Amphetamine, kava, kava vehicle, and saline for the low-dose training group (left panels) and high-dose training group (right panels) as a function of test dose. The top graphs reflect responding $60 \mathrm{~min}$ following administration of the test drug (Test One), and the bottom graphs reflect responding 90 min post-administration (Test Two). 
Figure 2.
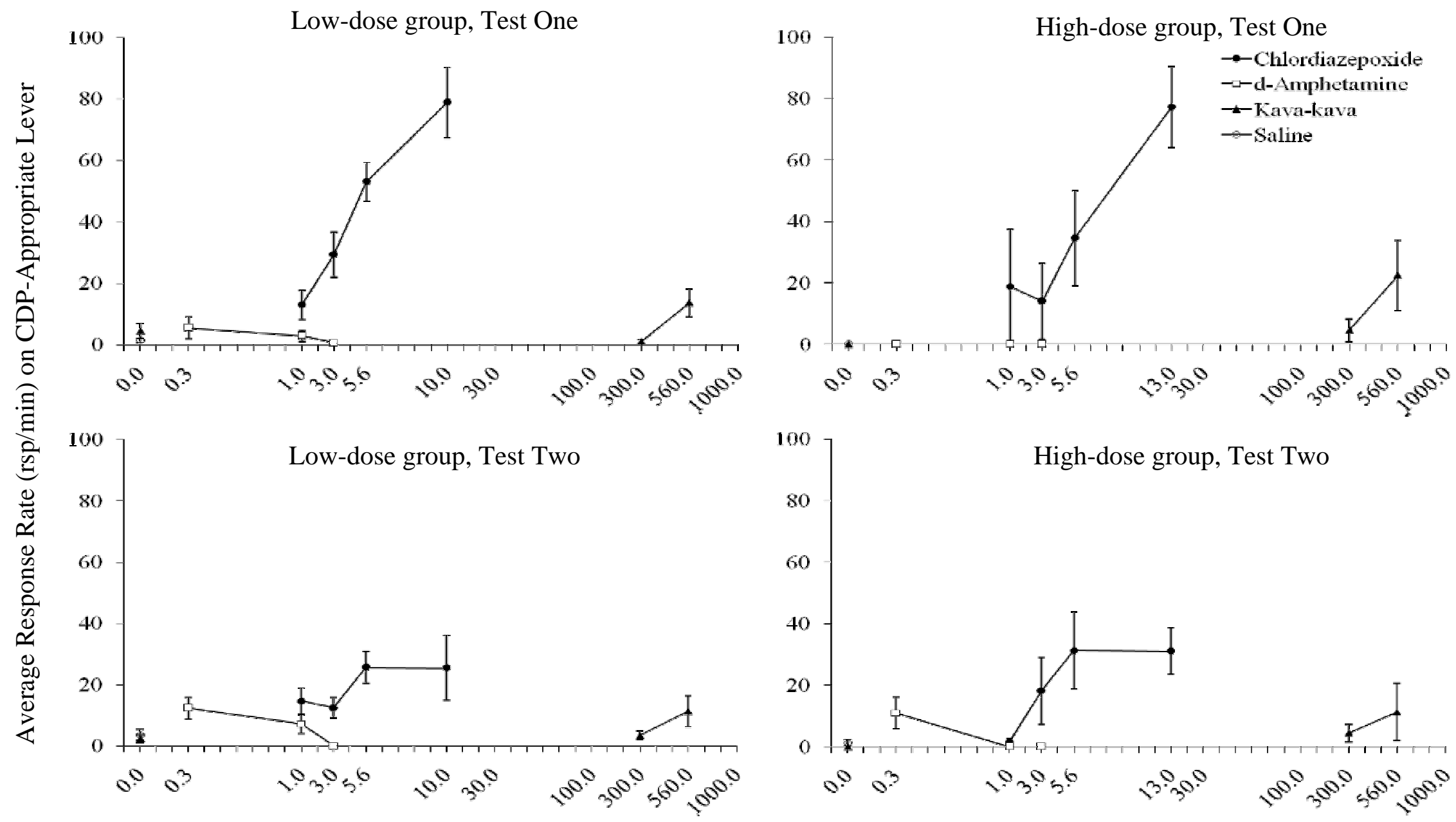

Drug Dose (mg/kg)

Figure 2. Mean response rate and SEM on the CDP-appropriate lever for each of the test doses of CDP, $d$-amphetamine, kava, kava vehicle, and saline for the low dose training group (left panels) and high-dose training group (right panels) as a function of test dose. The top graphs reflect responding $60 \mathrm{~min}$ following administration of the test drug (Test One), and the bottom graphs reflect responding 90 min post-administration (Test Two). 
During Test Two, the average response rate on the CDP-appropriate lever was lower than that found during Test One for both groups. As found in Test One, the average response rate for the low-dose group (25.5 rsp/min) was lower than that found for the high-dose group (31.0 rsp/min). In general, the response rate on the CDP-appropriate lever systematically decreased as a function of dose for both groups. Group means and individual data for response rate on CDP-appropriate lever in Test Two are presented in Figure 2 and Table 6, respectively.

Generalization of saline vehicle. The average percentage of total responses and response rate on the CDP-appropriate lever during both tests following saline administration was also calculated. Saline served as the vehicle for both CDP and negative control $d$-amphetamine. For both groups, no substitution following saline administration was found in either test. Group means and individual data for percent responding on the CDP-appropriate lever during Test One are presented in Figure 1 and Table 2, respectively. Test Two group means (Figure 2) and individual data (Table 6) for response rates on the CDP-appropriate lever following saline administration are also presented.

Generalization of d-amphetamine (negative control). In general, evidence of substitution of $d$-amphetamine was not found during Test One. However, partial substitution was found in Test Two. The 3-way repeated measures ANOVA revealed a main effect of percentage of total responses emitted on the CDP-appropriate lever for $d$-amphetamine of test time, $F(1,7)=39.5$, p $<0.01$, and group, $F(1,7)=20.6, \mathrm{p}=0.05$. No main effect was found for dose, $F(2,14)=2.5, \mathrm{p}$ $=0.11$. Because only three of nine subjects fulfilled the response requirement following administration of $d$-amphetamine $3.0 \mathrm{mg} / \mathrm{kg}$, these data were not included in the analyses. Administration of negative control $d$-amphetamine $(0.3-3.0 \mathrm{mg} / \mathrm{kg})$ did not occasion responding indicative of substitution during Test One in either group of rats (Figure 1). The low- 
dose group (6.7-16.3\%) emitted a higher average percentage of responses more than the highdose group (0.0-0.0\%) on the CDP-appropriate lever following administration of $d$ amphetamine. With the exception of one subject (S70-7), partial substitution of $d$-amphetamine was not found in individual subjects (Table 3). The average response rate on the CDPappropriate lever in Test One was found to systematically increase as the dose of $d$-amphetamine decreased in the low-dose group (Figure 2). The low-dose group $(M=17.6, S E M=3.3)$ had a higher average percentage of total responses on the CDP-appropriate lever following $d$ amphetamine administration than the high-dose group $(M=5.6, S E M=2.8)$. Response rates on the CDP-appropriate lever during Test One for individual subjects are presented in Table 7.

During Test Two, administration of the lower doses of $d$-amphetamine resulted in responding on the CDP-appropriate lever indicative of partial substitution in both groups (Figure 1). As was found in Test One, the average percentage of responses and response rate on the CDP-appropriate lever following $d$-amphetamine administration was slightly higher in the lowdose group (0.0-42.4\%) than the high-dose group (0.0-30.9\%). On average, the percentage of total responses emitted on the CDP-appropriate lever following $d$-amphetamine administration was significantly more during Test Two $(M=21.0, S E M=4.2)$ than during Test One $(M=6.1$, $S E M=2.0)$. Individual data for average percentage of total responses on the CDP-appropriate lever are presented in Table 1. The average percentage of total responses (Figure 1) and response rate (Figure 2) on the CDP-appropriate lever systematically increased as the dose of $d$ amphetamine decreased. Response rates on the CDP-appropriate for individual subjects (Table 7) during Test Two are presented.

Generalization of kava. In general, partial substitution of kava was found in both groups at Test One, but only the low-dose group during Test Two. The percent of total responses 
emitted and response rate on the CDP-appropriate lever was functionally related to dose with an average of 38.7\% maximum substitution at any dose. The 3-way repeated measures ANOVA revealed a significant main effect of kava dose, $F(2,14)=6.1, \mathrm{p}=.01$ with average percentage of total responses on the CDP-appropriate lever. No main effects were found for test time, $F(1$, $7)=.03, \mathrm{p}=.86$ or group, $F(1,7)=1.76, \mathrm{p}=.23$.

Partial substitution of kava was found for kava $560 \mathrm{mg} / \mathrm{kg}$ in both groups during Test One (Figure 1). Subjects emitted a significantly higher average percentage of total responses on the CDP-appropriate lever following administration of kava $560 \mathrm{mg} / \mathrm{kg}(M=10.1$, $S E M=2.6)$ than kava $300 \mathrm{mg} / \mathrm{kg}(M=31.7, S E M=7.6)$. A subsequent t-test revealed a significant difference of percentage of total responses on the CDP-appropriate lever between kava vehicle and kava $560 \mathrm{mg} / \mathrm{kg}(\mathrm{p}<.05)$. The average percent responding on the CDP-appropriate lever was slightly higher in the low-dose group (maximum $38.7 \%$ ) than the high-dose group (maximum 31.4\%). However, two rats in the low-dose group and one rat in the high-dose group did not respond on the CDP-appropriate lever following administration of kava (Table 4). Partial substitution was not found following administration of kava $300 \mathrm{mg} / \mathrm{kg}$, except for one rat in the low-dose group (S60-2). Following administration of kava, the response rate on the CDPappropriate lever was functionally related to dose. No substitution was found in either group during Test One for kava vehicle. Group data for response rates on the CDP-appropriate lever are presented in Figure 2. Response rates on the CDP-appropriate lever individual data are presented in Table 8.

Partial substitution of kava was found during Test Two for kava $560 \mathrm{mg} / \mathrm{kg}$ in the lowdose group only (Figure 1). In this group, the average percentage of total responses and response rate on the CDP-appropriate lever were slightly lower in Test Two than Test One following 
administration of kava $560 \mathrm{mg} / \mathrm{kg}$. Following administration of kava, the response rate on the CDP-appropriate lever was functionally related to dose in both groups. On average, administration of kava $300 \mathrm{mg} / \mathrm{kg}$ did not result in partial substitution for either group. However, two subjects in the low-dose group and one subject in the high-dose group did emit at least 20\% of the total responses on the CDP-appropriate lever. No substitution was observed following administration of kava vehicle in either group during Test Two (Figure 1). Individual data for percent responding (Table 4) and response rate (Table 8) on the CDP-appropriate lever during Test Two following kava administration are presented.

\section{Discussion}

Dose-dependent substitution of CDP was found in both the low and high-dose training groups. Although the low-dose group appeared to be more sensitive to the effects of CDP because of the lower $\mathrm{ED}_{50}$ values, no significant differences were found between groups. The negative control $d$-amphetamine did not substitute for CDP in either group during Test One. However, during Test Two, marginal substitution was found in both groups at the lower doses of $d$-amphetamine. Kava $560 \mathrm{mg} / \mathrm{kg}$ was found to occasion partial substitution in both groups during Test One and only the low-dose group during Test Two.

Administration of kava $560 \mathrm{mg} / \mathrm{kg}$ resulted in partial substitution for the training dose of CDP in both groups 60 min post-administration (Test One). Ninety min post-administration (Test Two), partial substitution was observed in the low-dose group only. However, the extent to which kava $560 \mathrm{mg} / \mathrm{kg}$ generalized to the training dose was modest (i.e., 31.4\%-38.7\%). For some rats, full substitution was observed following administration of kava $560 \mathrm{mg} / \mathrm{kg}$. Individual differences in sensitivity to methods and drugs used in the present experiment may have contributed to the variability in substitution observed. Several procedural variables may have 
influenced the present results. One potential variable that may have influenced the findings is that the training doses of CDP may have engendered poor stimulus control for other potential $\mathrm{GABA}_{\mathrm{A}}$ agonists like kava. Perhaps utilizing a shorter-acting benzodiazepine (e.g., midazolam) for discrimination training may enhance stimulus control. It is possible that administration of kava results in effects that are more sedative than anxiolytic (see discussion below). Therefore, it may be worthwhile to investigate the discriminative-stimulus effects of kava in rats trained to discriminate a short-acting barbiturate from saline.

Perhaps characteristics of the particular preparation of kava used in this study may have influenced the present results. Kava dose-dependently increased the average percentage of total responding on the CDP-appropriate lever to a range considered as partial substitution. At higher doses, kava may fully substitute for CDP. It is possible that administration of kava had effects on motivation (i.e., kava had anorexic effects). However, this is unlikely because subjects consumed all of the daily food that was provided 30 min following completion of the session. Previous research had indicated that particular kavalactones, particularly dihydrokavain, might mediate effects similar to benzodiazepines in behavioral tests (e.g., Feltenstein et al, 2003). Perhaps the preparation of kava extract used in this study did not have a high enough content of a particular kavalactone to occasion full substitution. The samples used by Feltenstein et al. that resulted in anxiolytic effects contained 15.0-67.5\% dihydrokavain, while the sample used in this experiment contained $18.6 \%$ dihydrokavain. Future work may test effects of different samples of kava extract containing higher concentrations of different kavalactones. Another possibility would be to examine effects of dihydrokavain or other kavalactones administered alone, instead of within the kava extract. However, there is reason to believe that the extract was behaviorally active, as subjects were visibly sedated and sometimes failed to respond following administration of kava 
$560 \mathrm{mg} / \mathrm{kg}$. Four subjects in the high-dose group died or had to be euthanized due to gastrointestinal complications that may or may not have been related to kava administration. In 2002, the FDA issued a warning pertaining to the potential harmful effects of kava. It is possible that the doses of kava used were having harmful effects on the subjects. Because of the potential toxic effects of this drug, future research investigating kava's use as an herbal medicine is warranted.

Another variable that may have influenced the present results was the change in training doses in both groups. In order to obtain a reliable discrimination between CDP and saline, a few modifications were made to the procedure. Administration of CDP $3.0 \mathrm{mg} / \mathrm{kg}$ failed to generate discriminated responding in the low-dose group. When the training dose was increased to 5.6 $\mathrm{mg} / \mathrm{kg}$ and the response requirement was reduced to FR 10 (see discussion below), most subjects acquired the discrimination. In the high-dose group, CDP $17.0 \mathrm{mg} / \mathrm{kg}$ suppressed responding almost entirely. When the training dose was decreased to CDP $13.0 \mathrm{mg} / \mathrm{kg}$, all subjects acquired the discrimination and the average response rate was only slightly lower than that of the lowdose group.

In addition to modifying the training doses of CDP, the reinforcement schedule had to be modified during training in order to facilitate discrimination. The VI component of the tandem VI 30-s FR 10 was removed, and only an FR 10 schedule of reinforcement was in effect. As a result, this resulted in data that were more quantal in nature, due to the all-or-none responding that often occasion FR schedules of reinforcement (e.g., Stolerman, 1993).

Another variable that may have influenced the results of the present experiment is the altered route of administration during testing. In order to test substitution of kava, drugs had to be administered orally on test days. Although CDP was still administered i.p. on training days, 
using the p.o. route of administration on testing days did not seem to affect substitution of CDP. The training doses of CDP administered orally engendered full substitution in both training-dose groups. The subjective effects of the drugs appeared to be the same, regardless of route of administration.

Interestingly, during Test Two the negative control $d$-amphetamine $0.3 \mathrm{mg} / \mathrm{kg}$ (in both groups) and $d$-amphetamine $1.0 \mathrm{mg} / \mathrm{kg}$ (in the low-dose group) partially substituted for CDP. However, the extent of the substitution was only marginal, and may have been due to effects of extinction in Test One (i.e., no food received after fulfilling the response requirement during Test One might occasion responding on opposite lever during Test Two). It may be useful to examine sessions in which effects of different time courses are examined individually (e.g., Anderson and van Haaren, 1999). These authors investigated the hypothesis that a drug's time-course effects may be evaluated within subjects and within a single session. Two generalization tests were given following cocaine administration, one at $10 \mathrm{~min}$ and one at $30 \mathrm{~min}$. However, the authors found the effects of exposure to extinction in Test One on responding during Test Two to be negligible. There were no differences in generalization gradients that were obtained 30 min after cocaine administration, regardless of whether another gradient was obtained after a generalization test was conducted 10 min post-administration. This may not have been the case in the present study.

In conclusion, in the present study it was found that kava $560 \mathrm{mg} / \mathrm{kg}$ partially substituted for the training stimuli in both the high- and low-dose training groups $60 \mathrm{~min}$ (both groups) and 90 min (low-dose group only) post-administration. At 60 min post-administration, kava 560 $\mathrm{mg} / \mathrm{kg}$ shared some discriminative-stimulus effects with the training stimuli in both groups. It appears as though in the high-dose group, the discriminative-stimulus effects of kava $560 \mathrm{mg} / \mathrm{kg}$ 
were diminishing 90 min post-administration. However, kava 560 mg/kg still partially generalized to the training stimulus in the low-dose group 90 min after administration. At present, it is unclear why kava failed to fully substitute for the training doses of CDP. Although it is possible that administration of kava may not fully substitute for benzodiazepines, further research is warranted to rule out other variables that may have influenced the present results. Future research may incorporate a different benzodiazepine as a training drug to perhaps engender stronger stimulus control. Another possibility that kava failed to fully substitute may be due to the particular preparation of kava used in this study, or the chemical structure of kava extract itself. In the case that kava acts more as a sedative than anxiolytic, it may generalize to a different drug class (e.g., barbiturate). Future research should also examine the possibility that extinction during Test One may have resulted in responding on the opposite lever during Test Two by incorporating a phase in which subjects are presented with tests at different times. 


\section{References}

Anderson, K.G., \& van Haaren, F. (1999). Cocaine discrimination and time-course effects in male and female Wistar rats. European Journal of Pharmacology, 382, 69-74.

Branch, M. (1991). Behavioral pharmacology. In I. Iversen and K. A. Lattal (Eds.), Experimental analysis of behavior, Part 2. (pp. 21-77). Amsterdam: Elsevier.

Ernst, E. (2006). Herbal remedies for anxiety- a systematic review of controlled clinical trials. Phytomedicine, 13(3), 205-208.

Feltenstein, M., Lambdin, L., Ganzera, M., Dharmaratne, H., Nanayakkara, N., Khan, I., \& Sufka, K. (2003). Anxiolytic properties of Piper methysticum extract samples and fractions in the chick social-separation-stress procedure. Phytotherapy Research, 17, 210216.

Fleshler, M., \& Hoffman, H.S. (1962). A progression for generating variable-interval schedules. Journal of the Experimental Analysis of Behavior, 5(4), 529-530.

Ganzera, M., \& Khan, I.A. (1999). Analytical techniques for the determination of lactones in Piper methysticum Forst. Chromatographia, 50, 649-653.

Garret, K.M., Basmadjian, G., Khan, I., Schaneberg, B., \& Seale, T. (2003). Extracts of kava (Piper methysticum) induce acute anxiolytic-like behavioral changes in mice. Psychopharmacology, 170, 33-41.

Geier, F., \& Konstantinowicz, T. (2004). Kava treatment in patients with anxiety. Phytotherapy Research, 18, 297-300.

Jussofie, A., Schmiz, A., \& Heimke, C. (1994). Kavapyrone enriched extract from Piper methysticum as modulator of the GABA binding site in different regions of the brain. Psychopharmacology, 116, 469-474. 
Malsch, U., \& Kieser, M. (2001). Efficacy of kava-kava in the treatment of non-psychotic anxiety, following pretreatment with benzodiazepines. Psychopharmacology, 157, 277283.

O’Sullivan, H., \& Lum, K. (2004). The poisoning of 'awa: the non-traditional use of an ancient remedy. Pacific Health Dialogue, 11, 211-215.

Rex, A., Morgenstern, E., \& Fink, H. (2002). Anxiolytic-like effects of Kava-kava in the elevated plus maze test- a comparison with diazepam. Progress in NeuroPsychopharmacology \& Biological Psychiatry, 26, 855-860.

Singh, Y.N. (1992). Kava- An Overview. Journal of Ethnopharmacology, 37(1), 13-45.

Singh, Y.N. (2005). Potential for interaction of kava and St. John's wort with drugs. Journal of Ethnopharmacology, 100, 108-113.

Smith, K., Dharmaratne, H., Feltenstein, M., Broom, S., Roach, J., Nanayakkara, N., Khan, I., \& Sufka, K. (2001). Anxiolytic effects of kava extract and kavalactones in the chick social separation-stress paradigm. Psychopharmacology, 155, 86-90.

Stolerman, I. P. (1993). Drug discrimination. In: van Haaren, F., (Ed.). Methods in Behavioral Pharmacology, pp. 217-243. Amsterdam: Elsevier.

van Haaren, F. (1992). Response acquisition with fixed and variable resetting delays of reinforcement in male and female Wistar rats. Physiology \& Behavior, 52, 767-772. 


\section{Curriculum Vitae Natalie R. Bruner}

\section{PERSONAL DATA}

School Address: $\quad 53$ Campus Drive Morgantown WV, 26505

Phone: (304)293-2001

E-mail: $\quad$ natalie.bruner@mail.wvu.edu

\section{EDUCATION}

2005-present West Virginia University

Major: Behavior Analysis
Degree: M.A. \& Ph.D. expected

Advisor: Karen G.

Anderson, Ph.D.

Title of Master's Thesis: "Discriminative-stimulus and time-course effects of kava-kava (Piper methysticum) in rats"

Workinq Title of Dissertation: "Response acquisition, delay discounting, and ethanol self-administration in the prenatally stressed rat"

2001-2005

Illinois Wesleyan University

Degree: B. A.

Major: Psychology

Ph.D.

Advisor: James D. Dougan,

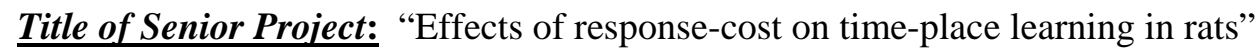

\section{AWARDS AND HONORS}

- Dean’s List, Illinois Wesleyan University, Fall 2003- Spring 2005

- Social Chair, Psi Chi National Honor Society, Illinois Wesleyan Chapter, Fall 2004-Spring 2005

- Member, Psi Chi National Psychology Honor Society, Inducted Spring 2004

- Details Coordinator, Psychology Club, Fall 2004-Spring 2005

- West Virginia University Psychology Department Alumni Fund Award, April 2006

\section{SCHOLARLY ACTIVITY}

Norris, J., Bruner, N., \& Dougan, J. (2005). Effects of response-cost in a time-place learning paradigm.. Poster presented at the annual convention of the Association for Behavior Analysis, Chicago, IL. 
Bruner, N.R. \& Anderson, K.G. (2006). Effects of corticosterone on delay discounting in rats. Poster presented at the annual meeting of the Southeastern Association for Behavior Analysis, Greenville, SC.

Bruner, N.R. \& Anderson, K.G. (2007). Effects of response-contingent delayed food-paired and non-paired stimulus presentations on lever-press acquisition in rats. Poster to be presented at the annual convention of the Association for Behavior Analysis. San Diego, CA.

Bruner, N.R. \& Anderson, K.G. (2007). Effects of acute morphine on delay discounting in rats. Poster presented at the annual meeting of the Southeastern Association for Behavior Analysis, Athens, GA.

Bruner, N.R. \& Anderson, K.G. (2007). Effects of acute morphine on delay discounting in Lewis and Fischer 344 rats. Poster presented at West Virginia University Neuroscience Retreat, Wheeling, WV. Poster formally presented at the annual meeting of the Southeastern Association for Behavior Analysis, Athens, GA.

Bruner, N.R. \& Anderson, K.G. (2008). Effects of acute and chronic morphine on delay discounting in Lewis and Fischer 344 rats. Symposium talk to be presented at the annual convention of the Association for Behavior Analysis. Chicago, IL.

\section{PROFESSIONAL EXPERIENCE}

\section{Research}

- Research assistant: Research investigating psychophysiological effects of a homesexual confederate in humans (Spring 2002).

- Research assistant: The effects of response-cost on time-place learning in rats (Fall 2002Spring 2003).

- Independent Research Project: The effects of response-cost on time place learning in rats (Fall 2004-Spring 2005).

- Research Assistant: Research investigating the effects of corticosterone on impulsive choice in rats (Fall 2005-Spring 2006).

- Master's Thesis: Discriminative-stimulus and time-course effects of kava-kava (Piper methysticum) in rats (Summer 2006-present). 
- Research Assistant: Grant-funded research project examining strain differences between Lewis and Fischer rats using a delay-discounting procedure. (Spring 2007-Present)

Teaching Experience

- Graduate teaching assistant: Introduction to Psychology (Fall 2005-Summer 2006)

- Graduate teaching assistant: Behavior Principles Lab (Fall 2006-Spring 2007)

\section{Skills and Abilities}

- Information-seeking skills relevant for research in the psychological sciences including, PsycINFO, PubMed, PsycArticles

- Trained in appropriate care and use of laboratory rodents and drug administration, intraperitoneal and subcutaneous injections

- Working knowledge of the Windows 98, 2000, \& XP

- Working knowledge of Microsoft Office 97 \& 2000: Word, PowerPoint, and Excel

- Working knowledge of SPSS, SigmaPlot and MED-PC

- Working knowledge of Microsoft Visual Basic 6.0

-

\section{PROFESSIONAL AFFILIATIONS}

- Southeastern Association for Behavior Analysis - Student Member

- Association for Behavior Analysis - Student Member

PROFESSIONAL SERVICE

- Student representative for West Virginia University’s Behavior Analysis Training Committee

\section{REFERENCES}

Available Upon Request

Digitally signed by John $\mathrm{H}$. Hagen 